\title{
Interactive comment on "Parallel functional and stoichiometric trait shifts in South-American and African forest communities with elevation" by Marijn Bauters et al.
}

\section{Anonymous Referee \#2}

Received and published: 28 July 2017

\section{General comments}

The manuscript by Bauters et al. presents an interesting analysis based on a detailed survey of tree species occurrences and their functional traits along two altitudinal transects. The main findings concerning the similar shifts in community weighted means of the key leaf traits for American and African altitudinal transects is stunning and of potential interest to a broad audience. Having that said, there are several issues that need to be improved.

Specific comments

My major point concerns a decoupling between results and theoretical background. 
The reasoning behind the study needs to be better developed and introduced.

Understanding the links between nutrient availability and species composition or biomass production is certainly a key for tropical forests. Nevertheless, it is not fully clear how particularly this study contributes to this understanding. For instance, the first two lines in Abstract state: "Elevational gradients are an empirical tool to assess long-term forest responses to environmental change. We studied whether functional composition of tropical forest along elevational gradients in South America and in Africa showed similar shifts." I do not understand how these sentences are connected. If the shifts are similar, what can this result tell us about forest responses to environmental change?

Similarly, lines 33-34: "This highlights the importance of nutrient availability for tropical forest in a changing world."

I feel that this sentence is not a sufficient explanation for the main result found here. Why is nutrient limitation important and how this study contributed to this conclusion?

Moreover, as nitrogen concentration changes with both elevation and altitude, how can we know that nutrient concentration (and not temperature) is the key driver of species composition?

I recommend authors to better develop and explain the hypotheses tested.

Second, it is being argued that phosphorus rather than nitrogen is the key nutrient limiting biomass production (and perhaps also species distribution) in tropical forests (Aragao et al. 2009, Quesada et al. 2009). Why this study focuses on nitrogen concentration only? This issue should be discussed.

Aragão, L. et al. 2009. Above-and below-ground net primary productivity across ten Printer-friendly version Amazonian forests on contrasting soils. - Biogeosciences 6: 2759-2778. Quesada, C. A. et al. 2009. Regional and large-scale patterns in Amazon forest structure and function are mediated by variations in soil physical and chemical properties. - Biogeosci.

Discussion paper 
Discuss. 6: 3993-4057.

Third, If "Elevational gradients are an empirical tool to assess long-term forest responses to environmental change" (first line of Abstract), how general these results can be? E.g. could we find similar pattern along latitudinal transects?

Lastly, the first paragraph of Discussion is difficult to read. I recommend starting with the main results, how are these results linked with the predictions and what is the possible implication. It is unclear what "the general characteristics" means and what "vegetation structure" means and what "structural characteristics" means

Technical comments:

Line 53: extra “,”

Line 95: Unclear whether tree height or carbon stock was estimated using pantropical relationship. Perhaps delete the comma after "(AGC)"?

Line 509: "2" in upper case (R2adj)

Interactive comment on Biogeosciences Discuss., https://doi.org/10.5194/bg-2017-136, 2017. 